\title{
Miragens de assombro em uma inestética da arte
}

\author{
Mauricius Martins Farina*
}

http://dx.doi.org/10.22409/poiesis.1829.161174

\begin{abstract}
RESUMO: A arte e o seu conceito relacional ocorrem a partir de algo que não pode ser encurtado pelo simples desígnio de uma classificação autonomista. Entretanto, esta condição se relaciona com seus próprios instintos de sobrevivência e sua necessidade se estabelece no princípio alargado das possibilidades de expressão, de limites a serem superados. Ao pensar sobre a arte em um construto de continuidades, enfrentamos um paradoxo localizado entre o ser em si e o ser de si que a arte propõe no mundo. Os princípios autofágicos dos autonomistas já não se sustentam como um argumento único, porque foram confrontados com a realidade, em sua inestética, por isso recuperamos experiências políticas.
\end{abstract}

PALAVRAS-CHAVE: arte moderna, autonomia, arte contemporânea

RESUMEN: El arte y su concepto relacional ocurren a partir de algo que no puede ser acortado por el simple designio de una clasificación autonomista. Pero esta condición se relaciona con sus propios instintos de supervivencia, y su necesidad se establece en el principio ampliado de las posibilidades de expresión, de límites a ser superados. Al pensar en el arte en un constructo de continuidades, enfrentamos una paradoja localizada entre el ser en sí y el ser de sí que el arte propone en el mundo. Los principios autorreferentes de los autonomistas ya no se sostienen como un argumento único, porque se han enfrentado a la realidad, en su inestabilidad, por lo que recuperamos experiencias políticas.

PALAVRAS-CLAVE: arte moderno, autonomía, arte contemporáneo

\footnotetext{
* Mauricius Martins Farina é professor do Instituto de Artes da Universidade Estadual de Campinas, líder do Grupo de Pesquisa Estudos Visuais (UNICAMP/CNPq) e Bolsista PQ2 do CNPq. E-mail: mauriciusfarina@gmail.com.
} 


\section{Utopias revisitadas}

A arte moderna, na experiência de seus artistas, produziu um deslocamento radical naquela razão descritiva das aparências, cuja tradição secular se permitiu abandonar, ao potencializar a formação material das obras que se experimentavam na diversidade de suas possibilidades, como causa de seu próprio destino. Ao agirem nessa direção autonomista, os artistas modernos promoveram um deslizamento de possibilidades diante de uma ideia de arte que se transformava, e de termos classificatórios que já não eram definidos em condições de relativa estabilidade. As imagens produzidas pelos artistas modernos promoverem um estranhamento das ordens do clássico e do anticlássico, que eram entendidas no conjunto de uma tradição circular, e assim, potencializaram o que queriam expressar em outros termos. Essas experiências modernas permitiram supor uma necessidade de desfiguração visível do assemelhado ao mundo descrito como paisagem, como ambiência, seja em plano geral ou em detalhe. Posicionando seus termos estruturais como um fim em si, as experiências modernistas, na causa de sua própria liberdade, propuseram um fazer em diálogo com suas potências de enunciação nas mais variadas possibilidades exploratórias, não mais a partir de um assunto que de fora se punha na imagem, em contextos épicos, realistas, simbólicos. Assim, as tendências autonomistas fizeram-se valer a partir de seus predicados e concretudes formais assumidos como conceitos.

Não nos interessa traçar uma diacronia a respeito desta condição modernista, apenas estabelecer, a princípio, um marco conciliatório ao apontar para um processo culturalmente sintomático das relações do fazer, do sentir e do expressar, a partir dessa primeira virada modernista na direção do contemporâneo. Pensamos naquilo que se faz envolto nestas realizações da tradição moderna, cuja causa de quebras de um contínuo, paradoxalmente, é uma continuidade dele, e cujas ações embreantes estão a funcionar na própria constituição da contemporaneidade. As camadas de alteridade que nos definem, em uma direção contrária da possibilidade autonomista, ainda que em sua circunstância de influência e de esgotamento, nos aproximam das aparências do mundo e de suas próprias contradições. Muitos procedimentos relacionados à arte moderna, no campo das artes visuais, foram inventariados a partir da presença de uma noção ruptura e de autonomia formal o que é amplamente visível, seja na potencialização dos elementos de sua própria articulação de plasticidade, seja no processo 
histórico das experiências anteriores que permitiram essa possibilidade. Os processos de criação da arte moderna estavam implicados na causa da sua sobrevivência através de um jogo de possibilidades inovadoras e experimentais, posicionando-se belicamente diante de uma tradição estabelecida culturalmente e com a qual se conectavam por filiação e pertencimento.

A necessidade de ruptura com a tradição das belas artes que se evidenciou nos inícios do século XX pelo viés radical de novos procedimentos ou emancipações formais, em movimentos artísticos como o suprematismo, o fauvismo, o cubismo, ocorreram para superar modelos tradicionais implicados em causas que já não Ihes serviam no ambiente de uma tradição burguesa. Com pretensões à imobilidade estética no qual se originavam, essas experiências foram fundamentais e serviram para garantir a própria sobrevivência da arte. É fato, entretanto, que precisamos ter cuidado com o tempo e com a distância que temos do passado; atribuir um jogo estabelecido entre tradição e ruptura como uma chave única para entender as vanguardas, pode ser também, um raciocínio redutor. Estamos diante de um problema no qual a arte moderna e seu conceito de síntese derivam de algo que não pode ser encurtado pelo simples desígnio de uma classificação autonomista. Assim, nos vemos perante procedimentos históricos da arte do século XX, cuja coleção situada ao alcance dos melhores museus, de uma forma vasta e inclusiva, mas que muitos só conheceram por livros, e agora por imagens na internet, não pode ser diminuída por fantasmas de sua própria presença. Ao nos aproximarmos dessas obras que hoje habitam os museus, estamos diante dessa encarnação da materialidade das obras, assim podemos perceber experiências potencialmente vivas de um mundo, que é o nosso, e que ainda está em transformação. Se considerarmos, em presença das obras, que o tempo é apenas um dos marcos possíveis, poderemos perceber a potência experimental impregnada dos instintos e dos conceitos de contemporaneidade de seus autores que pensam nas obras que fizeram.

O caminho anunciado para a abstração das referências foi do abstracionismo informal ao geométrico, a potenciação cromática com o fauvismo, ou ainda, os problemas da espacialidade cubista, eventos formalmente exponenciais nos inícios do século XX. Entretanto, estes não se constituíram como as únicas formas de manifestação no ambiente modernista, ainda que, a partir disso, tenham se desdobrado na experiência autonomista mais radical que estava direcionada à presença de uma experiência material diante da pintura, uma experiência ótica necessariamente aberta à subjetividade, mas implicada da ação dos corpos do artista e depois 
do seu visionador, em um diálogo com o espaço aberto de uma visualidade organizada nos campos de uma experiência artística potencial, que se manifestou com o expressionismo abstrato entre os anos 1940 e 1950.

A pintura agora se tornou uma entidade que pertence à mesma ordem espacial a que pertencem nossos corpos; não é mais o veículo de um equivalente imaginado dessa ordem. O espaço pictórico perdeu seu "interior" e tornou-se inteiramente "exterior". O espectador não pode mais escapar para dentro do espaço pictórico a partir do espaço em que ele mesmo se encontra. Se o espaço pictórico chega a enganar seu olho, é através de meios óticos e não pictóricos: por meio de relações de cor e forma amplamente divorciadas de conotações descritivas, e normalmente por meio de manipulações em que a parte superior e a parte inferior, assim como a frente e o fundo, torna-se intercambiáveis. (GREENBERG, 1996, p. 147)

O mundo moderno, em suas várias ocorrências, transformou radicalmente os modos de ser e de estar, tanto em usos quanto em costumes, e não pode ser pensado, nesses termos, a partir de uma simples chave autonomista; afinal, sua própria nomenclatura estava comprometida com os elementos plurais e contextuais desta cronotopia diante da qual se estabelecia. O modernismo autonomista defendido por Greenberg, considerava que a experiência da arte, travada fora de seus próprios espaços, não seria digna de maiores observações. Assim, se revelava o que consideramos uma precariedade crítica, fundada em preceitos nostálgicos e metafísicos que se afirmam como verdade, em detrimento de outras possibilidades igualmente dignas. Na impossibilidade de determinar mais que seu próprio lugar, estas ideias sobreviveram, aliando-se àquelas noções impregnadas de um juízo estético purista contra as quais as próprias vanguardas quiseram romper. Essa condição autonomista, debatida entre o kitsch das massas o qual despreza e um mundo superior que supõe se reconectar, ocorre sob a pena de esquecer o mundo real, de deixar passar sua condição expressiva presente nos sintomas daquilo que se configura em sua presença. Essa condição teve reverberação em muitos textos críticos posteriores que, ao contrário de buscar entender as formas de expressão do contemporâneo em sua imanência, se posicionam com amargura, diante das lógicas de um mundo desconfigurado pelo consumo das massas, de sua cultura visual reprodutiva, revelando nostalgias idealistas de um tempo perdido. 


\section{Outras formas de uma mesma forma}

É importante considerar, ainda nesse ambiente das vanguardas históricas, outras experiências, com outro tipo de consequências e relacionamentos políticos com a própria realidade, tais como o expressionismo na Alemanha (tratado por Adolf Hitler com arte degenerada), o dadaísmo e o surrealismo, ambos catastroficamente impactados pela pathosformel das desigualdades e violências da vida. Nesse contexto histórico, as velhas tradições burguesas, que estavam a se afirmar e a se renovar, o faziam diante das condições socioculturais que aumentavam os problemas individuais, estabelecendo-se em um cenário complexo de transformações, que situou o século XX entre o fascismo, o socialismo e o capitalismo, que se apresentaram como estruturas visíveis diante de uma rede de derivações oportunistas de toda a ordem que ainda nos impactam. Os sistemas da arte moderna, a partir da Primeira Guerra Mundial (1914-1918), já não se estabeleciam a partir de um simples debate entre uma oportunidade ou outra, ou sobre a beleza, ou sobre sua múltipla possibilidade diante da feiura, mas sobre a instauração de uma enorme diversidade que se faria definitiva entre os marcos de renovação e de ruptura, que se configuravam diante de uma necessidade aparente. 0 movimento dadaísta (Zurique, 1916), que ocorreu a partir da iniciativa de um grupo de artistas politicamente indignados com a hipocrisia racionalista, alguns deles desertores da Primeira Guerra, no qual inicialmente se destacaram Tristan Tzara, Hugo Ball e Hans Arp, tinha objetivos revolucionários e amplamente direcionados a situar o nonsense como uma possibilidade potencialmente expressiva, diante de um racionalismo bélico desenvolvimentista, que tinha suas origens e consequências relacionadas às contradições da sociedade europeia e de sua necessidade de poder.

Com Marcel Duchamp, que transformou-se em um dos mais importantes e influentes artistas do século XX, as ações artísticas demonstraram-se de forma propositiva em uma articulação conceitual e crítica sobre os próprios processos da arte, de seus sistemas, de suas questões de manufatura, que foram pensados e considerados a partir de outras possibilidades, tais como a recodificação, o ready-made e as ações de apropriação autoral, procedimentos que se configuram no campo da arte contemporânea e que se adiantaram, em muitos anos, a respeito da própria discussão sobre a noção de autoria efetivada pelo pós-estruturalismo. 
Muitos adeptos do dadaísmo se ligaram, a partir de 1924, ao movimento surrealista que se apresentou ao mundo a partir de uma perspectiva ligada a princípios herdados da psicanálise e do próprio nonsense, em uma perspectiva simbólica ligada às noções da inquietante estranheza que foram apresentadas por Freud, e adaptada por Breton em uma perspectiva essencialmente poética tratando dos recônditos mais indefinidos e subterrâneos do inconsciente, até um encantamento multiculturalista, colocando em questão mais uma vez, as velhas certezas burguesas e capitalistas do mundo moderno. O surrealismo se aproximou, à sua maneira, de um princípio político alinhado com as esquerdas, constituindo-se como uma corrente contrária ao modernismo com seus princípios simbólicos que, ao contrário, nasciam de pulsões originadas do mundo e com objetos desse lugar. A experiência surrealista foi colocada no exílio cultural durante os anos 1940/50, mas reviveu, com uma força inequívoca, e se atualizou na arte abjeta dos anos 1980/90, quando pudemos pensar em um surrealismo retornado pela via do choque e do trauma diante desse próprio ambiente capitalista que parece não ter mais oposições, desde a queda do muro em Berlim e o fim da União Soviética, o que configura uma imposição sinistra.

Es posible que la creencia de que el capitalismo ya no tiene un exterior sea el mayor ideologema posmoderno que existe, el que subyace a los otros postulados sobre el eclipse de este espacio, el fin de esta narrativa. Lo que no resulta claro es si la sensación posmoderna de un fin puede ser en sí misma una narrativa, capaz de proyectar distintos pasados que nunca existieron (por ejemplo, un yo burgués fijo, una vanguardia verdaderamente transgresora) para impedir así futuros alternativos probables. Con esta cautela en mente, una respuesta posible al eclipse contemporáneo de lo siniestro es que mientras haya represión, su retorno siniestro existirá. Uno también podría plantear, contra la "compresión" posmoderna de lo surreal, que es justamente ahí donde se encuentra el mundo soñado del capitalismo en su forma más consistente y más completa. Es decir, uno podría insistir que el surrealismo no es de todo anticuado. (FOSTER, 2008, p. 329-330)

Diante da realidade da vida, reconhecemos que a sobrevivência de princípios atrelados ao nonsense dadaísta e ao surrealismo estão presentes em muitas ocorrências da arte contemporânea, e ainda são possíveis como princípios de ideia, tendo como estabelecido que o nonsense é de fato um sentido político, e como tal se configura além de um pleno exercício metafísico das vanguardas autonomistas, com o expressionismo abstrato e com outros 
abstracionismos que antes dele e depois dele continuaram a existir. A frequência política, que fez sintonizar a presença dadaísta na arte contemporânea, tem relação com uma mesma condição incoerente e arrogante surgida como causa da modernização do mundo industrializado e que, desde a crise traumática das duas guerras mundiais (e da segunda em particular), fez da cultura capitalista (com seus tantos desdobramentos nominais) uma atualidade incômoda, transnacional. Isso nos permite considerar, desde o niilismo, o deslocamento e a histerese das narrativas utópicas do humanismo, do socialismo, uma falta de sentido na alteridade materializada nos termos de um suposto individualismo que surge como consequência de uma crise de oportunidades ou de uma escravidão transparente que nos é determinada pelas lógicas mecânicas da própria sobrevivência do sistema social, determinado pelas lógicas do consumismo e da dependência econômica.

Esses acontecimentos, demarcados pela história, apresentaram também uma nova via de oportunidades e foram importantes, entre tantas razões, para trazer ao debate uma vertente de ocorrências interligadas, entre o dadaísmo e o surrealismo, e serve para demonstrar que os processos de autonomia da arte moderna não são únicas ocorrências desse período. Os episódios autonomistas modernos, como referido por Lucy Lippard ${ }^{1}$ nos termos do expressionismo abstrato, estavam desde sempre apartados do surrealismo, exatamente por estarem claramente demarcados por uma busca de independência da descrição do real, ou de suas aparências assemelhadas, e diziam respeito, em um contexto mais amplo, aos problemas da forma e da necessidade de construção dos sujeitos modernos em sua plena autonomia expressiva. Questão que se propõe como uma causa continuada de processos de aproximação com o romantismo que, em uma constante relacionada ${ }^{2}$, deriva de outras ocorrências interessadas nas experiências radicalizadas pelas faturas artísticas em sua busca metalinguística. A questão relacionada com a arte pictórica, que se fazia submeter, desde o renascimento, pela aplicação ilusionista do espaço perspectivo, e depois pela afirmação da expressão, era também um processo de transformação e de elaboração da experiência visual atuando sempre em favor da própria construção do sujeito moderno e de sua autonomia desejada.

A questão anterior relacionada com aquilo que a arte se fazia submeter, desde o renascimento, com a introdução ilusionista do espaço perspectivo, era também um processo de transformação e elaboração da experiência visual atuando sempre em favor da própria construção do sujeito moderno e de sua autonomia desejada. A política da experiência autonomista da 
arte, defendida e relacionada aos artistas do expressionismo abstrato e de seus mestres antecessores, seria uma versão burguesa e bem resolvida da arte norte-americana, defendida como uma experiência libertária e individualizada da arte. Entretanto, essa energia não durou muito tempo; este mesmo mercado, ávido por novidades, agora se interessava pela arte pop, pelo novo realismo e por muitas outras ações da arte contemporânea, entendida nos termos da ampliação de espaços e de modalidades. Mas se quisermos olhar com certa sutileza, poderemos perceber em uma via paralela do modernismo autonomista, uma condição essencialmente política, ou de reverberação política, impactada pelos problemas sociais, cuja causa era essencialmente traumática, e se fazia permear por uma plêiade de transitividades poético-visuais, agindo no átimo de suas ocorrências, como embreantes de oportunidades, ou mesmo de visagens sobre a realidade em curso, em ações que posteriormente seriam recuperadas como em um salto. A década de 1960 efetivou-se com a condição de uma retomada do eixo de necessidades e de influências do mundo real, em sua expressão artística renovadora, diante da subjetividade desses sujeitos supostamente vencidos pela "lógica dos supermercados", entretanto, em uma posição claramente rompedora diante da pureza íntima da experiência sensível e dramática do espaço, particularmente através da pintura moderna nos anos anteriores.

A condução neodadaísta continha um discurso político de negação da cultura e dos sistemas autoritários, e os formalistas, em seus processos autofágicos, consideravam que os processos simbólicos da arte estariam implicados em retóricas desnecessárias à própria necessidade da arte como experiência material, exatamente porque estavam envolvidos em assuntos da mundanidade em crise, algo que em seus próprios meios e circunstâncias se fazia anunciar a partir da noção de uma outra experiência conceitual. Este tipo de expressão, em seus desdobramentos já com a arte pop, foi considerada por muitos como superficial, uma vez que parecia condicionada aos modismos da sociedade de consumo e de sua cultura visual medíocre e comercial. De fato, muitos dos detratores da arte pop não a perceberam como uma reconexão aos princípios realistas e paradoxais do dadaísmo, não porque não quisessem, mas porque desprezavam essas origens. Algumas obras de Marcel Duchamp aparecem com datas duplas, 1917-1964, 1920-1964, 1913-1964, servindo para demonstrar que as oportunidades de recomposição de uma ideia, através de uma obra inicialmente perdida, podem ocorrer em um outro viés, onde os ready-mades de Duchamp foram percebidos na potência em que se revelavam naqueles anos 1960 em Nova York. 


\section{A arte sobrevive à arte}

A política da experiência autonomista da arte, defendida e relacionada aos artistas do expressionismo abstrato e de seus mestres antecessores, seria mais que uma versão burguesa e bem resolvida do mercado e da arte, ainda que tenha sido absorvida e tenha ajudado a criar, mas foi entendida como uma experiência libertária e individualizada da arte. Entretanto essa energia da experiência e da reativação da pintura moderna pela via do expressionismo abstrato foi sucedida por outras experiências, pela arte pop, pelo novo realismo e por muitas outras ações da arte contemporânea, entendida, a partir disso, nos termos da ampliação de espaços e de modalidades. A arte sobrevive à arte, em sua ampliação de domínios e na tentativa de estabelecimento de paradigmas, sejam eles concretos ou abstratos, realistas ou conceituais. Sua natureza é múltipla; por isso, não se pode deter em esquemas ou formas de entendimento simplistas.

Se uma experiência artística não se sobrepõe a outra, mas a ela se acrescenta, não é por isso apenas singularidade ou experiência isolada, já que considera as tantas camadas repertoriadas antes dela. Assim, nos resta considerar que a natureza da arte tem relação com o que faz de uma experiência artística uma obra de arte e, sobre isso, temos em conta uma vasta coleção de textos que já foram feitos e outros tantos estão por se fazer. O que pretendemos diante disso é ressaltar que essas experiências históricas se oportunizam em circunstâncias relacionais, com outras possibilidades, que também as determinam. E ainda, que possuem não apenas um aspecto, mas muitos outros. Uma das coisas que podemos declarar sobre a experiência artística é que ao se fazer diante de uma circunstância improvável, na qual não podemos distinguir ou hierarquizar uma experiência sobre a outra, reconhecemos que ela surge a partir do processo complexo que se relaciona. Portanto, sendo uma obra de arte um trabalho, temos uma existência que se põe em campo, diante das circunstâncias da vida, de sua própria vida, e esta existência está configurada em termos relacionais e plurais. Assim, ao se constituir como arte, nessa condição, tratamos de uma nomeação atribuída em princípio pelo próprio artista que integraliza, em sua natureza procedimental, o ser da coisa que se faz arte. Por isso, esta sua materialização será submetida aos próprios critérios do artista e, se ele tiver meios para isso, aos complicados meandros da arte, onde sua homologação (que é sempre um ato político), quem sabe, poderá atingir aquele lugar onde as obras definitivas são preservadas na história e em seus arquivos, que se fazem a partir disso. 
Se algo se faz com a arte, apesar dessa experiência se tornar pública ou não, é porque temos uma contingência estabelecida por um território assim nomeado. Nesses termos, o juízo de valor, a oportunidade de gosto, é algo que ocorre em uma circunstância complexa, diante da qual o visionador se disponibiliza para uma troca possível. Entretanto, a coisidade da arte, como tal, se liga a outras circunstâncias que não se podem assemelhar a uma lógica de paixões ou vaidades discursivas, tal como em uma escolha por uma arte realista ou abstrata. As experiências da arte, diante da contemporaneidade do mundo, estão abertas e disponíveis para serem o que são, sem hierarquias ou determinismos procedimentais; entretanto, nessa condição plural, nem todas as obras de arte se disponibilizam para considerar a realidade como um argumento de sua própria contextualidade, diante desse mundo e das circunstâncias que, evidentemente, sempre estarão a lhes afetar.

\section{O contexto da arte, em outros contextos}

Considerar a arte, no contexto da cultura latino-americana, em seus processos e circunstâncias, sem juízos de valor ou afirmações nacionalistas, implica em reconhecer uma diferença de oportunidades entre seus pares, em um nível de agravamento social extremamente complicado. A escassez de oportunidades socioeducativas, que é histórica, está implicada na organização social estratificada impactada em uma profunda desigualdade entre seus pares. No Brasil, não tivemos guerras em defesa da liberdade e pela superação das diferenças que tenham sido vencidas pelos seus proponentes. Ao contrário, o poder institucional (contra o qual se levantam os insurgentes) sempre se fez sobrepor e soube transformar seus inimigos em sujeitos exóticos ou em seres alucinados, messiânicos, como foi Antônio Conselheiro em Canudos. Questões como essa estão presentes em nossa própria fundação histórica e mestiça, por força das circunstâncias ou de tragédias, em uma geopolítica contaminada pela invasão, determinada pelo colonialismo. Diante disso, nossa impotência, que é apagada pelo esquecimento de nossas origens, não se pode acomodar ao sermos transformados no que somos, sujeitos contemporâneos ensimesmados, quando percebemos que nossa diferença, diante do outro, se configura a partir desse corte que nos configura como rizomas em nosso suposto pertencimento. 
A possibilidade de uma leitura diversa, autóctone, descolonial, da cultura e da arte latino-americana, pode significar um avanço importante na direção de uma melhor localização de nossos próprios interesses culturais; entretanto, ela esbarra em diversos problemas conjunturais, que não se explicam apenas nessas condições. Ao recorrermos à matriz europeia moderna, nos termos do dadaísmo ou do surrealismo que foram reativados na pós-modernidade, com o neodadaísmo e outras denominações, podemos considerar que uma dimensão crítica e política, em suas próprias circunstâncias, se estabeleceu como potência poética diante de uma dificuldade que se fez oportunidade. A potência desse sentido traumático que nos aproxima do contemporâneo é explicitado pela distopia social. A condição de precariedade social não é apenas localizada em termos geográficos, ela é muito mais extensa.

Desde a queda do muro de Berlim, a Europa viu acontecer algumas práticas artísticas coletivas, distribuídas em torno das práticas comunitárias e do ativismo, determinadas pela própria constatação de que as instituições da arte já não podem abarcar outros modos de representação fora de seus domínios e reconhecimentos, agindo como verdadeiras "utopias artísticas da revolta", tema tratado por Julia Ramírez Blanco, nos casos específicos de Claremont Road, Reclaim the Streets, La Ciudad de Sol, publicado pelos Cadernos Arte Cátedra. A discussão sobre a ocorrência de limites e de seus transbordamentos, considerando as inúmeras experiências que estas práticas relacionadas ao ativismo artístico ou artivismo, a relação com as práticas comunitárias que em suas ações de transbordamento institucional estão de certa forma interagindo com as instituições, seja para negá-las ou para constatar seu desinteresse em uma demarcação de espaço relacionado ao território da arte contemporânea. A ação política pode ser conduzida em atos de profusão performática e aí a circunscrição, ou a nomeação dessa experiência, pode ser reveladora de processos contraditórios de aceitação e de negação do próprio conceito de arte.

Quando os minimalistas - em caso citado por Didi-Huberman em O que vemos, o que nos olha - Donald Judd e Frank Stela se indignavam com Mark Rothko por sua condução cromática "ilusionista" e propugnavam sua política de "não-representação", como destacou Didi-Huberman, eles se esqueciam de que eles estavam operando no sistema da arte e que sua atitude de negação da expressão era, de outra forma, um ocaso relacionado àquela primeira ideia concreta que Wassily Kandinsky havia descrito no pequeno texto $A$ arte concreta, publicado por 
Herschel Chipp no livro Teorias da arte moderna. As derivações das ações políticas expandidas ao campo da arte se implicam também de uma fronteira alargada desse próprio campo, aí de mão e contramão temos inúmeras possibilidades dialógicas.

A definição de campos em termos estéticos não se situam mais entre beleza ou feiura ou feiura bela. Em O abuso da beleza, Arthur Danto traça um panorama histórico deste problema e constata o papel fundamental que os modernistas tiveram nessa transformação de paradigmas. Outra questão se coloca nestes tempos supostos de uma vitória do capitalismo cultural quando o mundo se encontra estetizado em uma circunstância em que o próprio capitalismo é o artista, ou seja, o capitalismo se utiliza das formas da arte para aplicar em suas atividades de consumo (LYPOVETSKY; SERROY, 2015). Com isso esbarramos em um problema complicado tendo em conta essa influência da arte, que é também uma condição estética globalizada em termos de suas oportunidades e seus espetáculos. O próprio Greenberg, ao qual nos referimos aqui, em outra circunstância afirmou que "quando a arte é examinada como arte e nada mais que arte, o problema da relação entre a arte e a vida, a estética e o valor moral, é irrelevante". (2002, p. 117)

Lembramos A morte de Marat (1793), de Jacques-Louis David, pintado em homenagem ao falso herói jacobino Marat com todas as consequências históricas e posterior degredo do artista. Ainda assim, uma obra de arte fundamental. Essa contradição entre o ser da arte e suas relações contextuais, ainda que possa ter várias mortes e desaparecimentos, se conduz por um problema fundamental que se localiza no seu próprio acontecimento. Muitas formas alternativas e processos residuais entendidos como arte e suportados como tal podem não ser absorvidos pelos regimes institucionais e políticos que cercam a arte. Ainda assim, e sobretudo, a experiência que se define nesses termos se conecta a uma condição de supor e recolocar no mundo uma nova origem, mesmo que a partir de outras, caso muito corrente nos eixos reprodutivos da pós-modernidade.

Nos parece que seja mais coerente, ou justificado, abordar que muitos dos trabalhos apresentados nos rótulos experimentais do artivismo e das práticas colaborativas enfrentam enormes dificuldades de legitimação institucional, sendo essa uma questão importante. Muitas destas experiências recusam ser entendidas como arte de uma forma autodeclarada, por saberem, 
de antemão, que o circuito institucional não terá interesse em sua validação. Outro problema, ainda mais recorrente, se relaciona às curadorias institucionalizadas pela arte contemporânea que, ao demonstrarem interesse por essas práticas, estariam, de fato, consumindo-as em favor de seus próprios interesses, nos termos mais amplos dessa condução, na qual os artistas, em específico, são devorados pelo saturnismo das instituições e de suas lógicas de produção de espetáculos.

A revolução proposta pelas vanguardas, em sua revolta com a beleza tradicional, foi feita em circunstâncias próprias, em uma cultura hegemônica e extensiva culminando no processo de globalização da cultura; entretanto, em estratificações geopolíticas bastante identificadas com o eixo europeu e norte-americano, e nessa condição, as outras culturas foram impactadas e se tornaram interessantes para esses públicos, na possibilidade de sua identificação com uma alteridade extensiva. Atualmente esses eixos ganharam outra extensão e mobilidade.

As relações culturais se ampliaram em lógicas de contato com o outro, de forma muito mais dialógica. Muitos artistas latino-americanos têm conseguido visibilidade e interesse em museus e centros de arte contemporânea do "primeiro mundo". Poderíamos citar: Lygia Clark, Hélio Oiticica, Tunga, Cildo Meireles, Gabriel Orozco, León Ferrari, Víctor Grippo, Waltércio Caldas, Guillermo Kuitca, José Bedia, Alfredo Jaar, Doris Salcedo, Alexander Apóstol, Marta Maria Pérez Bravo, Beatriz Milhazes, Rosângela Rennó, Vik Muniz, entre outros artistas de importância, sem esquecer de destacar o interesse que despertou, nas últimas décadas, o próprio modernismo latino-americano em coleções de museus como o MoMA, o Reina Sofia, o Guggenheim (em suas várias sedes) e o Centre Georges Pompidou, entre outros.

Nessa dimensão de oportunidades, a querela centro $x$ periferia precisa ser vista com o devido cuidado, espreitando sua inexistência com desconfiança, estabelecendo o problema a ser discutido de modo muito mais especificado que uma simples constatação de oportunidades abertas. Pensamos que este interesse se relaciona com várias questões, por exemplo: um interesse efetivo despertado pela diferença criativa, pelo encantamento com o outro em seu "esteticismo tropicalista", pela golfada de ar fresco e criativo em um ambiente complicado pelas diversas condições traumáticas e por uma cristalização acadêmica de difícil ultrapassagem. Ainda assim é preciso considerar que nestes territórios culturais organizados do primeiro 
mundo, onde habitam interesses que não souberam, ou não quiseram, equalizar suas diferenças culturais e que se impõem ao outro pela tecnologia que dominam, as crises de estratificação econômica e os êxodos dos povos em colapso para o território de seus antigos colonizadores, desenham um cenário de mudanças estruturais com forte carga política para a produção de sentidos distópicos, cujas consequências, ainda em curso, são imprevisíveis.

\section{Referências}

BLANCO, Julia Ramírez. Utopías artísticas de revuelta. Claremont Road, Reclaim the Streets, La Ciudad de Sol. Madrid: Cátedra, 2014. DANTO, Arthur C. O abuso da beleza. A estética e o conceito de arte. São Paulo: Martins Fontes, 2015.

D'ORS, Eugenio. Lo barroco. Madrid: Tecnos, 2015.

DUPUIS, Jules-François. História desenvolta do surrealismo. Lisboa: Antígona, 2000.

GREENBERG, Clement. Estética doméstica: observações sobre a arte e o gosto. São Paulo: Cosac \& Naify, 2002.

GREENBERG, Clement. Arte e cultura. São Paulo: Ática, 1996.

LIPPARD, Lucy R. (et alii). A arte pop. São Paulo: Verbo/EDUSP, 1976.

LIPOVETSKY, Gilles; SERROY, Jean. A estetização do mundo: viver na era do capitalismo artista. São Paulo: Companhia das Letras, 2015.

\section{Notas}

1 Lucy R. Lippard, escritora e crítica de arte norte-americana, autora de textos importantes sobre a arte contemporânea, entre eles: Six Years: The Dematerialization of the Art Object from 1966 to 1972 (Nova York: Praeger, 1973); Surrealists on Art. (Englewood Cliffs, N.J.: Prentice-Hall, 1970) e Pop Art (Nova York: Praeger, 1966).

2 Eugenio d'Ors (que não conheceu o expressionismo abstrato), no seu famoso texto sobre o barroco, formulou uma "teoria sobre os constantes históricos" que, segundo ele, nada têm com o problema do "eterno retorno", já que são derivados de outro contínuo. Para d'Ors, o barroco tem relação com tempos mais antigos, tais como o helenismo, mas também se comunica com o romantismo. (D'ORS, 2015, p. 65-68) 